\title{
Tissue Factor Controls the Balance of Angiogenic and Antiangiogenic Properties of Tumor Cells in Mice
}

\author{
Youming Zhang, " Youhua Deng, * Thomas Luther," Martin Müller, ${ }^{\star}$ Reinhard Ziegler, * Rüdiger Waldherr, * \\ David Mark Stern, ${ }^{\S}$ and Peter Paul Nawroth* \\ * Department of Medicine and Pathology, University of Heidelberg, D-69115 Heidelberg, Germany; ${ }^{\ddagger}$ Department of Patholology \\ and Medizinische Akademie, D-01307 Dresden, Germany; and ${ }^{\S}$ Department of Physiology, Columbia University, New York
}

\begin{abstract}
Meth-A sarcoma cells were stable transfected to overexpress ( sense construct) or underexpress (antisense construct) tissue factor. In vitro, there was no difference in plating efficiency or growth between these cell lines.

In vivo, tumor cells transfected to overexpress tissue factor grew more rapidly, and established larger and more vascularized tumors than control transfectants. Antisense transfectants grew the slowest and were the least vascularized. Anticoagulation of mice with warfarin did not alter the difference between these tumor lines. Tumor cells overexpressing tissue factor released more (compared with control transfectants ) mitogenic activity for endothelial cells in parallel with enhanced transcription of vascular permeability factor/vascular endothelial cell growth factor (VEGF/ VPF), and diminished transcription of thrombospondin (TSP2), a molecule with anti-angiogenic properties. Antisense tissue factor transfectants, while releasing the lowest amount of mitogenic activity, had increased thrombospondin and decreased VEGF/VPF transcription compared with control transfectants or wild-type cells. Experiments with these sense, antisense, truncated sense, or vector tumor lines gave comparable results in complete medium, serum free medium or in the presence of hirudin, indicating that the activation of the coagulation mechanism was not likely to be responsible for changes in tumor cell properties. These results suggest that tissue factor regulates angiogenic properties of tumor cells by altering the production of growth regulatory molecules of endothelium by a mechanism distinct from tissue factor activation of the coagulation mechanism. (J. Clin. Invest. 1994. 94:1320-1327.) Key words: tissue factor - coagulation - angiogenesis - endothelial cells • cancer
\end{abstract}

\section{Introduction}

Tissue factor, the principle initiator of coagulation in vivo ( 1 , 2 ), has been studied extensively in terms of its contribution to

Address correspondence to Dr. P. P. Nawroth, University of Heidelberg, Department of Medicine I, Bergheimer Strasse 58, D 69115 Heidelberg, Germany. 1994

Received for publication 29 July 1994 and in revised form 6 May

J. Clin. Invest.

(c) The American Society for Clinical Investigation, Inc.

0021-9738/94/09/1320/08 \$2.00

Volume 94, September 1994, 1320-1327 hemostasis and thrombosis (3). Consistent with a protective role in the hemostatic response, tissue factor is present only in subendothelial layers of the vessel wall, the interstitium, and is distributed throughout the subcutaneous tissue (4).

Although constitutive expression of tissue factor is a characteristic feature of multiple neoplastic cells, the role of this integral membrane protein in the biology of tumors is not clear. Reports from both clinical studies and experimental models describing a correlation between blockade of activation of coagulation and reduced tumor growth (5-7) suggest a potential contribution of the procoagulant mechanism, initiated by tissue factor, beyond hemostasis. Growth of solid tumors depends on their mitotic rate, their ability to evade the host response and the effectiveness with which they elicit neoangiogenesis.

The identification of tissue factor as a growth-related immediate early gene $(8-10)$, whose transcription is initiated coordinately with the induction of cell proliferation, suggests a possible role for tissue factor beyond the coagulation mechanism. Here we report that tissue factor regulates the balance of angiogenic and anti-angiogenic properties of tumor cells. By controlling tissue factor expression in Meth-A sarcoma tumor cells using molecular techniques, its role in these facets of tumor biology has been assessed. Expression of tissue factor is essential for the growth of solid tumors, since tissue factor controls the balance of angiogenic and antiangiogenic tumor cell activities.

\section{Methods}

Production of transfected tumor cells. Stable transfectants of Methylcholantrene-A-induced murine fibrosarcomas (Meth-A sarcoma) cells were prepared with tissue factor cDNA ( 7) (generously provided by D. Nathans, Baltimore, MD) cloned into pXT1 expression vector (Stratagene, La Jolla, CA), which contains the LTRs, a portion of the gag gene from Moloney Murine Leukemia Virus and the Herpes Simplex Thymidine Kinase promotor (Fig. 1) (11). The tissue factor insert spanned the whole translated region of the tissue factor gene, including sense, truncated sense (the latter producing an inactive tissue factor gene product due to deletion of the factor VII binding region and due to cloning it in the wrong reading frame), and antisense constructs, cloned into pXT1. pXT1 contains a selectable neomycin gene under control of the LTR, conferring G418 resistance (12). Transfection with each of these constructs or vector alone was performed using Lipofectin (GIBCO BRL, Gaithersburg, MD). $5 \mu \mathrm{g}$ of each plasmid DNA and 30 $\mu \mathrm{l}$ of Lipofectin $(1 \mathrm{mg} / \mathrm{ml})$ were separately diluted to $0.2 \mathrm{ml}$ with serum free medium (SFM) without antibiotics. After mixing, the DNA/ liposome complex formed in $20 \mathrm{~min}$ at room temperature. Subconfluent tumor cells were washed three times with serum free medium without antibiotics. $0.4 \mathrm{ml}$ of DNA/liposome mixture was added to the cells. 


\section{Expression System of Tissue Factor}

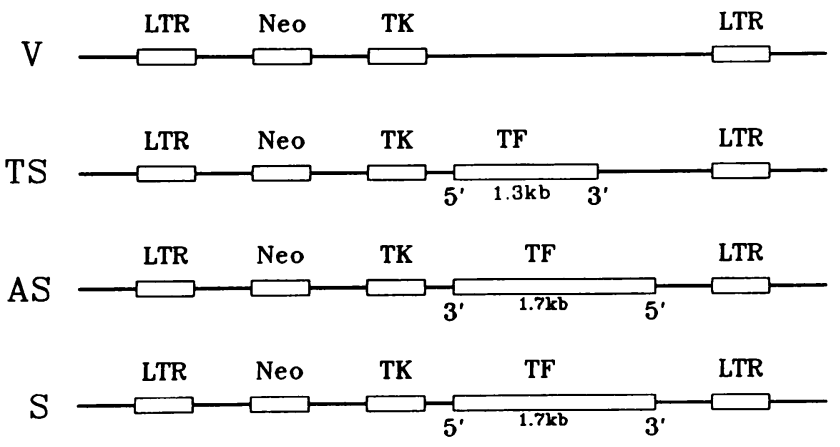

Figure 1. Expression system of mouse tissue factor. The full length of mouse tissue factor (mTF) cDNA was inserted into BglII site under TK promoter as both direction. Sense construct is $5^{\prime}-3^{\prime}$ and antisense construct is $3^{\prime}-5^{\prime}$. Truncated sense is partial of mTF gene spanned from $407 \mathrm{bp}$ to the end under TK promoter in $5^{\prime}-3^{\prime}$ direction. $V$, vector; $T S$, truncated sense; $S$, sense; $A S$, antisense; $L T R$, Moloney murine leukemia virus LTRs; Neo, neomycin-resistance gene; $T K$, herpes simplex thymidine kinase promoter; $T F$, mouse tissue factor gene.

The cells were cultured at $37^{\circ} \mathrm{C}$ and $5 \% \mathrm{CO}_{2}$ for $24 \mathrm{~h}$. An additional 3 $\mathrm{ml}$ of cell culture medium containing $20 \%$ FCS and antibiotics was added on the second day. On the third day cells were split and medium containing $10 \%$ FCS and $0.8 \mathrm{mg} / \mathrm{ml}$ of G418 (GIBCO BRL) was added (13). The selection medium was changed every $3 \mathrm{~d}$. Colonies of stable transfected cells were seen after 2 wk. All colonies (70-100 colonies in each transfectant) were used together for generation of a single cell line.

Determination of tissue factor expression. Western blots were performed as previously described (14). Tumor cells were scraped and washed three times with $0.9 \% \mathrm{NaCl}$, then lysed in $1 \times$ SDS loading buffer ( $50 \mathrm{mM}$ Tris, pH 6.8, $100 \mathrm{mM}$ dithiothreitol, $2 \%$ SDS, $0.1 \%$ bromophenol blue, $10 \%$ glycerol). The tumor cell lysate was sheared with a 27 -gauge needle and heated at $100^{\circ} \mathrm{C}$ for $10 \mathrm{~min}$. After being separated in SDS-PAGE, the proteins were electro-transfered onto Hybon-C extra membrane (Amersham International, Buckinghamshire, England). After the filter was dried on air for $20 \mathrm{~min}$, it was blocked with $5 \%$ nonfat milk in PBS, and incubated with anti-mouse tissue factor (described below) for $60 \mathrm{~min}$. The membrane was washed three times with PBS before incubation with second antibody (goat antirabbit IgG, conjugated with alkaline phosphatase). The color was developed by BCIP (5-Bromo-4-chloro-3-indolyl-phosphate, X-phosphate) and NBT (4-Nitro blue tetrazolium chloride) (Boehringer Mannheim Biochemica, Mannheim, Germany). The polyclonal antibody against recombinant mouse tissue factor was raised in rabbits. Its specificity has been demonstrated by reacting positive with cells transfected with tissue factor sense and negatively in cells transfected with tissue factor antisense cDNA. It also reacted negatively with mouse endothelial cells in vivo, while it reacted positive with wild-type tumor cells in vivo (data not shown). Furthermore the band recognized in wild-type tumor cells was the same as in tissue factor transfected cells (see Fig. $2 \mathrm{~A}$ ). Tissue factor activity was determined by a one stage clotting assay. Tumor cells were scraped, washed three times with BBS, pH 7.4 (15). For one stage clotting assay $10^{5}$ tumor cells were given to $100 \mu \mathrm{lBBS}$ and $100 \mu \mathrm{l}$ mouse citrated plasma. After mixing, $100 \mu \mathrm{l}$ of $100 \mathrm{mM}$ $\mathrm{CaCl}_{2}$ was added. The time until formation of definite fibrin strands at $37^{\circ} \mathrm{C}$ was noted. A standard curve for determination of relative tissue factor units was performed with different numbers of wild-type tumor cells. The clotting time obtained with $10^{5}$ wild-type tumor cells was defined as 100 arbitrary units (see Fig. 2 B).

Proliferation assay. For determination of tumor cell proliferation, transfectants were seeded ( 450 cells per $1.8 \mathrm{~cm}^{2}$ ) in $10 \%$ FCS, RPMI
1640, as shown in the Fig. $3 \mathrm{~A}$. For counting, cells were trypsinized and counted under the microscope. Cell counting was repeated two times by two of the investigators (Y. Zhang, and Y. Deng).

Tumor growth in vivo. For in vivo experiments $10^{6}$ cells in $100 \mu \mathrm{l}$ PBS, pH 7.4, were injected intracutaneously and the tumor size and weight determined at the indicated time points. Each mouse was injected with four different cell lines (tissue factor sense, antisense, truncated sense, and vector transfectants) at different places of the back to minimize intraindividual differences. Tumor weight was determined immediately after tumors were harvested at day 12 . Tumor size was determined by measuring the two largest diameters at the indicated times. With the exception of $2 \times 10 \mathrm{Balb} / \mathrm{c}$ nü-nü nude mice, we used $\mathrm{C}_{3} \mathrm{H}$ mice for the study of Meth-A sarcoma transfectant.

Immunohistochemistry. The tumor sections, or tumor cells growing on cover slips, were fixed in aceton for $10 \mathrm{~min}$ and washed two times with PBS. The sections or cells, were incubated with anti-meuse tissue factor antibody for $2 \mathrm{~h}$ at room temperature. Then the sections; or cells, were washed three times with $150 \mathrm{mM} \mathrm{NaCl}$ and $100 \mathrm{mM}$ Tris- $\mathrm{HCl}$, $\mathrm{pH} 7.5$, and incubated with second antibody (alkaline phosphatase conjugated for tumor cells; peroxidase conjugated for tumor sections) for $60 \mathrm{~min}$ at room temperature (16). After washing the sections, the-color was developed by BCIP (5-brom-4-chlor-3-indolyl-phosphat, X-phosphat) and NBT (4-nitroblautetrazoliumchlorid) (Boehringer Mannheim Biochemica) for fixed cells and by AEC (3-amino-9-ethyl-carbazole) (Sigma Chemical Co., St. Louis, MO) and $\mathrm{H}_{2} \mathrm{O}_{2}$ for tumor sections (17).

Determination of tumor vascularization. To visualize the vascularization of tumors, each animal was injected with $300 \mu \mathrm{l}$ of indian ink at $4 \mathrm{~min}$ before sacrifice and the skin was taken and dried. The free blood flow was estimated using $10 \mu \mathrm{m} \mathrm{E-Z} \mathrm{TRAC} \mathrm{ultraspheres} \mathrm{(Inter-}$ active Medical Technology, Los Angeles, CA). $5 \times 10^{5}$ of $10 \mu \mathrm{m}$ microspheres were injected into the left ventricel of a mouse and the tumor tissue harvested after $5 \mathrm{~min}$. After dissolving the tumor tissue the beads present in the tumor were counted and expressed as beads per gram tumor tissue.

Anticoagulation of mice with warfarin. Mice were maintained on drinking water supplemented with the warfarin (Sigma Chemical Co.) derivative 3-(a-acetonylbenzyl)-4-hydroxycoumarin $(8 \mathrm{mg} / 1)$ for $3 \mathrm{~d}$ before planting of tumor cells. The mice were given normal water after Meth-A cells were injected. Before carrying out an experiment with the anticoagulated animals, a factor $\mathrm{X}$ assay on the mouse plasma was performed. Only animals with factor $X$ levels of $<10 \%$ were used (18).

Endothelial cell studies. Human umbilical vein endothelial cells (HUVEC) were cultured as previously described (19). To obtain conditioned medium, tumor cell were cultured in serum free, or containing $10 \%$ FCS, RPMI 1640 without G418 over $12 \mathrm{~h}$. To study the effect of tumor cell conditioned medium on endothelial cell proliferation, HUVEC were seeded at the density shown in Fig. 7, $A$ and $B .1 \mathrm{ml}$ of tumor cell conditioned medium was added to $1 \mathrm{ml}$ of RPMI 1640 , containing $20 \%$ FCS, but no growth factors. When the effect of hirudin was tested, $0.5 \mathrm{U} / \mathrm{ml}$ of hirudin (Sigma Chemical Co.) were added to the tumor cell medium. The endothelial cells were counted by two investigators at the indicated time points.

Nuclear run on transcription assay. Nuclear run on transcription assay was performed essentially according to the method by Greenberg and Ziff (20), as modified by Almendral et al. (9). The cDNA of mouse vascular endothelial cell growth factor/vascular permeability factor (VEGF/VPF) ${ }^{1}$ was a generous gift of Dr. W. Risau (Max Planck Institute, Munich, Germany) the cDNA of mouse thrombospondin-2 (TSP2) was a generous gift of Dr. Bornstein (University of Washington, Seattle, WA). Nuclear run ons were performed with a 583-bp BamHIEcoRI insert of mouse VEGF gene and exon 4-7 of mouse TSP2 gene (514 bp). The result of the run on was quantitated by densitometry

1. Abbreviations used in this paper: VEGF, vascular endothelial cell growth factor; VPF, vascular permeability factor. 
A

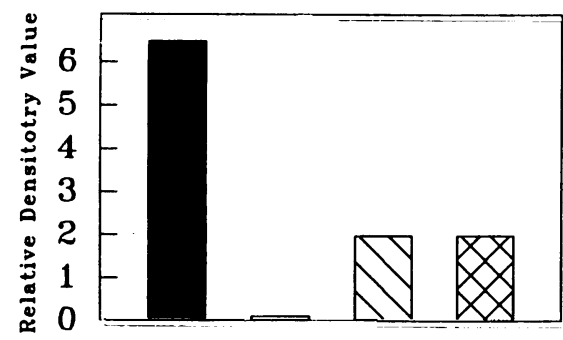

KD

67

43

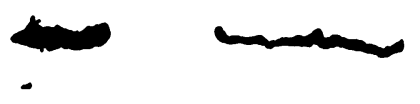

30

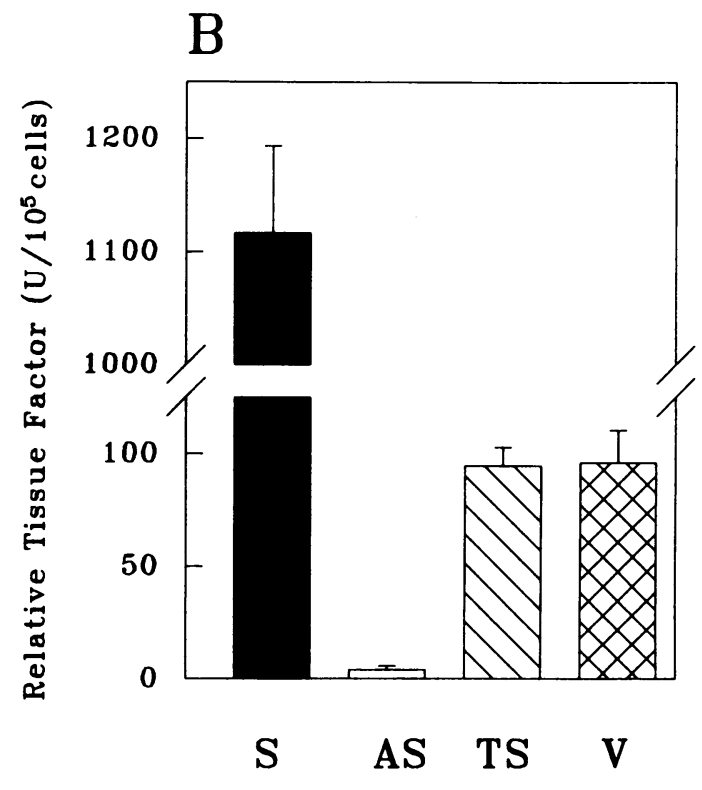

B

Figure 2. Characterization of transfectants. $(A)$ The tissue factor expression of transfected Meth-A cells was determined by Western blot and quantitated by densitometry, using an rabbit antibody against recombinant mouse tissue factor protein (ranging from aa 1-294, spanning the factor VII binding region). This antibody does not recognize the truncated tissue factor (in the wrong reading frame, ranging from 407-1780 bp). Each lane was loaded with $55 \mu \mathrm{g}$ of cell extract. Independent transfections of other Meth-A cell lines gave similar results with respect to tissue factor expression. $(B)$ One-stage clotting assay was used to measure biologic active tissue factor expressed ( see Methods) by the four lines tested. Cells overexpressing sense contain more biologic active tissue factor protein, than truncated sense or vector transfected cells $(P$

$<0.001$ ). Antisense transfected cells contain only very little or no tissue factor $(P<0.001)$ detectable by the methods used. Each column represents the mean, bar shows SD. The experiment was performed four times with three independently transfected cell lines. $(C)$ Expression of tissue factor antigen in cultured Meth-A cell transfectants (Immunohistochemistry, magnification is $\times 100)$. Abbreviations are as in Fig. 1.

using a Beckman DU 7400 Spectrophotometer. The values shown represent the value of the gene tested, minus the value of the negative control (pUC), normalized by division through GAPDH minus pUC.

Northern blot analysis. For Northern blots, inserts as above were labelled with $\left[\mathrm{a}^{-32} \mathrm{P}\right] \mathrm{dCTP}$ (Amersham) to a specific activity of $>10^{8}$ $\mathrm{cpm} / \mu \mathrm{g}$ DNA by the random prime technique (21). Total cellular RNA was purified by the guanidine isothiocyante cesium chloride method (22) and its concentration was determined by sample absorbance at 260 $\mathrm{nm} .15 \mu \mathrm{g}$ total RNA of each lane were size-fractioned through a $1.2 \%$ agarose gel in $0.7 \mathrm{M}$ formaldehyde and $20 \mathrm{mM}$ morpholinopropanesulfonic acid/5 mM sodium acetate/ $1 \mathrm{mM}$ EDTA, transferred to Hybond$\mathrm{C}$ extra filters (Amersham) and hybridized. Hybridization was performed as described (23) with minor modifications. Filters were prehybridized for $2 \mathrm{~h}$ and then hybridized for $12-16 \mathrm{~h}$ at $42^{\circ} \mathrm{C}$ in $25 \mathrm{mM}$ $\mathrm{K}_{3} \mathrm{PO}_{4}, \mathrm{pH} 7.4,5 \times$ SSC, $5 \times$ Denhardts solution, $50 \mu \mathrm{g} / \mathrm{ml}$ salmon sperm DNA, and $100 \mu \mathrm{g} / \mathrm{ml}$ yeast tRNA and $50 \%$ formamide. The blots were washed with $2 \times \mathrm{SSC}$ and $0.1 \%$ SDS at $65^{\circ} \mathrm{C}$ for $10 \mathrm{~min}, 1 \times \mathrm{SSC}$ and $0.1 \%$ SDS at $65^{\circ} \mathrm{C}$ for $30 \mathrm{~min}$, and $0.5 \times \mathrm{SSC}$ and $0.1 \%$ SDS at $65^{\circ} \mathrm{C}$ for $10 \mathrm{~min}$. Blots were exposed for 2 to $3 \mathrm{~d}$ to Amersham Hyperfilm at $-80^{\circ} \mathrm{C}$ with two intensifying screens. The density of autoradiographic signals was quantitated using a Beckman DU 7400 densitometer at 560 $\mathrm{nm}$ as above.

Statistical analysis. All values are given as mean. Bar shows standard division (SD). Means of groups were compared with analysis of variance using the Newman-Keul's test to correct for multiple comparisons. $P<0.05$ is considered statistically significant.

\section{Results}

Establishment and characterization of Meth-A fibrosarcoma cell lines expressing different levels of tissue factor. Meth-A 

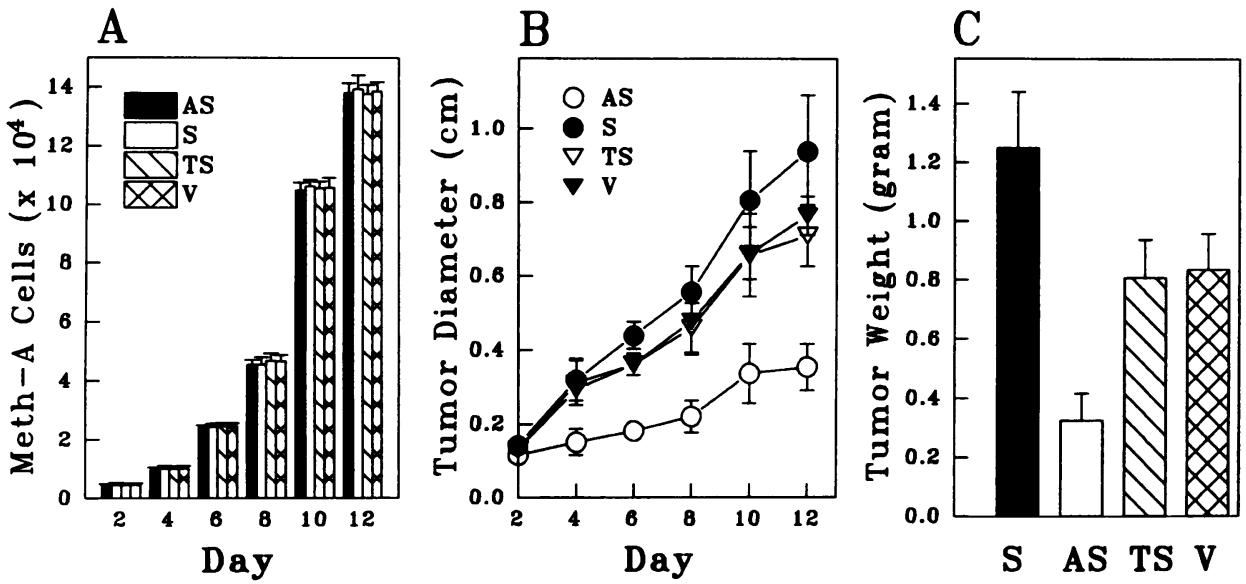

Figure 3. Role of tissue factor in Meth-A sarcoma growth. $(A)$ In vitro: proliferation of Meth-A sarcoma cells was studied in culture by counting cells after seeding with low density at the indicated timepoints. No difference in proliferation was noted $(P>0.1)$. The experiment was repeated three times with independently transfected cell lines. Each column represents the mean, bar shows SD $(n=3 \times 24)$. (B) In vivo: the growth in vivo was determined by measuring tumor size (diameter of tumors). Difference between cell lines expressing antisense and sense tissue factor was

significant $(P<0.01)$ after day 4 . The difference between lines expressing antisense and controls (vector and truncated sense) were also significant $(P<0.05)$ after day 4. Data show the mean, bar shows SD. The experiment was repeated three times $(n=3 \times 20)$. $(C)$ In vivo: the growth in vivo was determined after measuring tumor weight on day 12. Difference between cell lines expressing antisense and sense tissue factor was significant $(P<0.001)$. The differences between lines expressing antisense and controls (vector and truncated sense) were also significant $(P<0.001)$. Data show the mean, bar shows SD $(n=3 \times 20)$ of three independent experiments. Abbreviations are as in Fig. 1.

cells transfected with the full-length tissue factor sense construct expressed more tissue factor antigen and procoagulant activity than cells transfected with vector alone, based on Western blotting, one stage clotting assay (a measure of tissue factor activity) (Fig. 2, $A$ and $B$ ) and immunohistochemistry of cultured cells (Fig. $2 C$ ). The Meth-A cell line transfected with the antisense construct expressed little, if any, tissue factor. MethA cells transfected with vector alone or truncated sense tissue factor expressed levels of tissue factor identical to that observed with wild-type tumor cells. Expression of the indicated level of tissue factor by each of the above cell lines remained constant throughout these experiments and immunohistochemistry showed a homogenous expression of tissue factor antigen in the cell population (Fig. $2 C$ ).

Proliferation of Meth-A cell lines expressing different amounts of tissue factor was studied in culture by determining changes in cell number (Fig. $3 \mathrm{~A}$ ). Plating efficiency and growth of all four cell lines was identical, as was the expression of basic fibroblast growth factor, the latter based on Western blots (data not shown). This suggested that tissue factor expression is not an important factor for proliferation or survival of MethA cells in culture. Since survival and growth of solid tumors in vivo is not only dependent on.seeding efficiency and proliferation as tested in vitro, but also on vascularization and interaction with the immune system, we studied growth of the tumor mutants in vivo.

Cells from the four Meth-A transfectants were injected intracutaneously into $\mathrm{C}_{3} \mathrm{H}$ mice to examine tumor growth. Each mouse was inoculated with all four of the tumor lines, each in a different location. Tumor growth was quantitated based on tumor size/weight (Fig. 3, $B$ and $C$ ). In contrast to the comparable proliferation of the Meth-A cell lines in vitro, the antisense cell line grew slowly in vivo, compared with cells transfected with vector alone or the truncated sense construct. The difference observed between sense and antisense transfectants (Fig. $3 B$ ) was statistically significant after day $4(P<0.01)$. The difference between sense and vector was statistically significant after day $8(P<0.05)$. The growth of the antisense transfectants was significantly retarded already at day $4(P<0.05)$.
Consistent with these results the weight of sense tumors was greater than vector $(P<0.01)$ or truncated sense $(P<0.01)$, antisense transfectants weighted the least $(P<0.001)$ (Fig. 3 $C)$. Immunostaining for tissue factor demonstrated expression in the tumor cell population which was constant and comparable with that observed in tissue culture (Fig. 4). Tumor derived from antisense transfectants expressed much lower levels of tissue factor antigen, compared with vector or truncated sense transfectants. Tissue factor antigen was most prominent in tumor grown from sense transfectants. To exclude that the increased growth rate of sense transfectants is due to activation of coagulation, we repeated above experiments in mice anticoagulated with Warfarin, sense transfectants grew larger, and antisense transfectants showed a retarded growth (Fig. 5, A and $B$ ).

Mechanism of enhanced tumor growth of transfected cell lines expressing increased levels of tissue factor. These data indicated that expression of tissue factor by tumor cells facilitated tumor development in vivo. Since tissue factor did not directly influence tumor cell proliferation in vitro, two alternative hypotheses were considered. Tissue factor-mediated activation of coagulation, which has been speculated to result in a protective fibrin cocoon about the neoplasm, could prevent tumor destruction by host immunologic mechanisms (6). To assess this possibility, the experiments described above were repeated in nude mice with similar results (Fig. $5 \mathrm{C}$ ). In addition, the nonimmunogenic B16 melanoma line transfected with the antisense tissue factor construct demonstrated coordinate blockade of tissue factor expression and reduced growth in vivo (not shown). Furthermore, spontaneous rejection of each of the four Meth-A derived cell lines was observed in $\mathrm{C}_{3} \mathrm{H}$ mice at about $16 \mathrm{~d}$, consistent with comparable immunogenicity. These data suggested that mechanisms other than tumor-immune effector cell interactions were important in tissue factor-regulated growth of tumors.

An important factor in the successful establishment of a solid tumor nidus is the induction of neoangiogenesis, providing the tumor with nutrients critical for growth of the tumor cells (24). When vascularization of tumors derived from Meth-A 

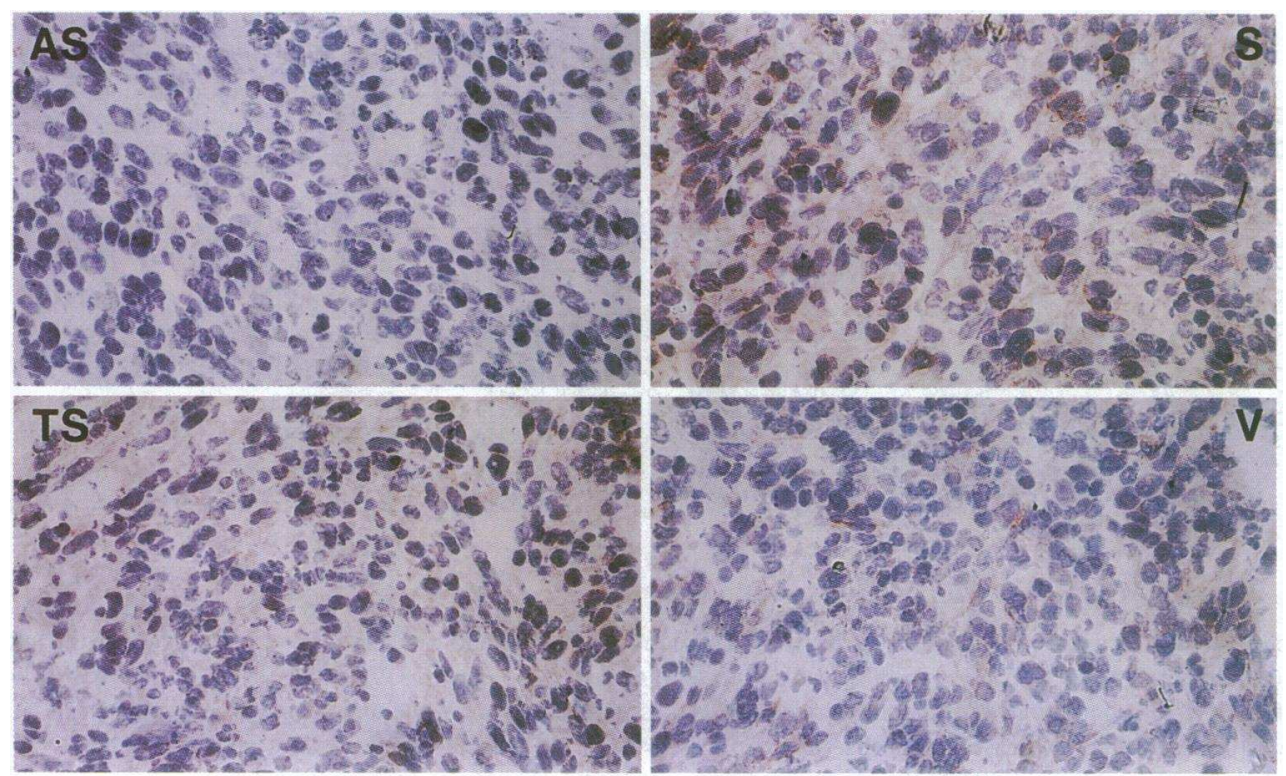

Figure 4. Expression of tissue factor antigen in tumor sections of stable Meth-A transfectants. Tumors were harvested on day 12 and processed for immunohistochemistry as described in Methods. Magnification is $\times 93$. Abbreviations are as in Fig. 1. cells transfected with each of the tissue factor constructs was compared, a greater density of vessels was evident in the tumors which expressed increased levels of tissue factor (sense construct) (Fig. $6 \mathrm{~A}$ ). Tumors expressing levels of tissue factor comparable to that observed in wild type Meth-A cells (i.e., those Meth-A cells transfected with vector alone or truncated tissue factor sense construct) showed a similar degree of vascularization, but less than in the sense construct. The lowest degree of vascularity was consistently seen in tumors expressing no tissue factor (antisense construct).

Estimation of tumor blood flow, based on perfusion with $10-\mu \mathrm{m}$ latex microspheres, which become trapped in the microvessels, supported the results of the morphologic studies (Fig. $6 \mathrm{~B}$ ). The number of microspheres per gram tumor tissue was the greatest in the tumors expressing high levels of tissue factor (sense construct), lower in the tumors expressing tissue factor levels comparable with wild type (vector or truncated sense construct, $P<0.005$ ), and the lowest in the tumors of the antisense construct $(P<0.001)$. Therefore tissue factor facilitates tumor growth in vivo by enhancing angiogenesis.

Effect of tissue factor on release of mitogenic activity for endothelial cells. This led us to examine if there was a relationship of tissue factor expression by tumor cells and the release of growth factor ( $s$ ) for endothelial cells. When the conditioned media of the four transfected cell lines was tested, a difference in their mitogenic activity for cultured endothelial cells was noted (Fig. $7 \mathrm{~A}$ ). Proliferation of human umbilical vein endothelial cells in medium not supplemented with growth factor was stimulated the most by supernatant from sense transfected Meth-A cells, while supernatant from vector or truncated sense
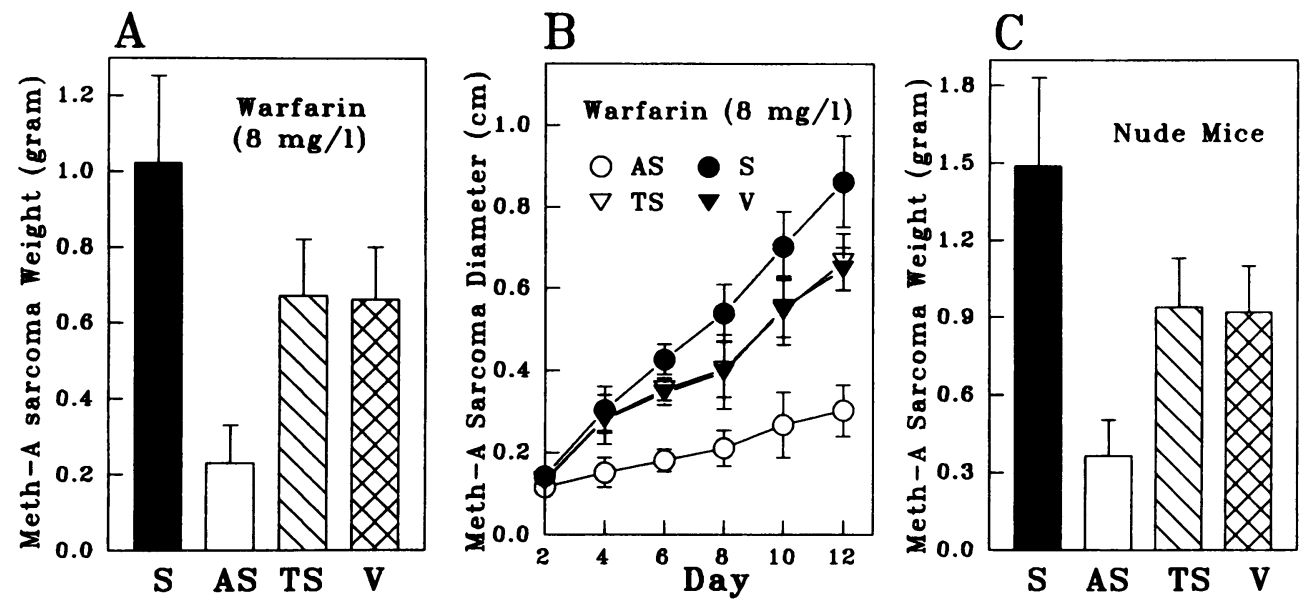

Figure 5. ( $A$ and $B$ ) Effect of anticoagulation on tumor growth in vivo. $(A)$ The growth in vivo was determined after measuring tumor weight on day 12 . The drinking water was supplemented with 8 $\mathrm{mg} /$ liter of Warfarin (see Methods). Difference between cell lines expressing antisense and sense tissue factor was significant $(P<0.001)$. The differences between lines expressing antisense and controls (vector and truncated sense) were also significant $(P$ $<0.005$ ). Data show the mean, bar shows SD. The experiment had been repeated three times ( $n$ $=3 \times 10) .(B)$ The growth of tumor in vivo in mice anticoagu-

lated with warfarin (see Methods) was determined by measuring tumor size (diameter of tumor) as in Fig. $3 \mathrm{~B}$. Difference between cell lines expressing antisense and sense tissue factor was significant $(P<0.05)$ after day 4 . The differences between lines expressing antisense and controls (vector and truncated sense) were significant $(P<0.05)$ after day 6. Data show the mean, bar shows SD. The experiment had been repeated three times $(n=3 \times 10)$. $(C)$ Tumor growth in nude mice. When tumors were implanted in nude mice, the tumor weight was similar as in Fig. $3 C$. Data show mean of two experiments $(n=2 \times 5)$. Abbreviations are as in Fig. 1 . 

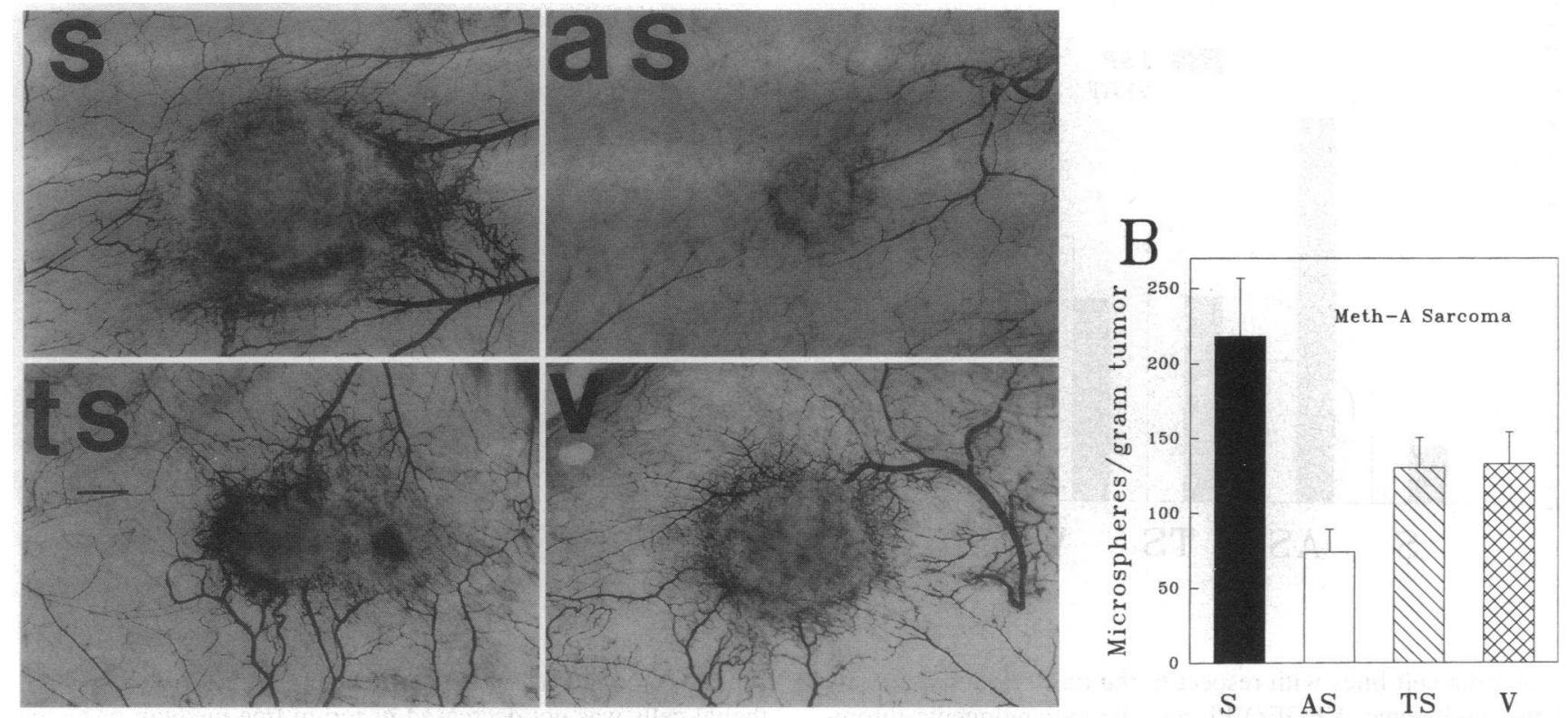

Figure 6. The role of tissue factor in tumor vascularization. $(A)$ The vessels growing towards the implanted tumor lines were visualized on day 6 . Animals were sacrificed and the vessels supplying the tumor were visualized by indian ink. Magnification is $\times 9$. $(B)$ Quantitation of differences in tumor vascularization with microspheres as described in Methods. Each column represents the mean, bar shows $\operatorname{SD}(n=2 \times 10)$. The experiment was repeated two times. Difference between cell lines expressing tissue factor sense and antisense was significant $(P<0.001)$, differences between cell lines expressing tissue factor sense and controls (vector or truncated sense) were also significant $(P<0.001)$. Abbreviations are as in Fig. 1 .

transfected Meth-A cells exhibited weaker stimulation of endothelial cell proliferation $(P<0.05)$. In contrast mitogenic activity of conditioned media from Meth-A cells not expressing tissue factor (antisense construct) was the weakest $(P$ $<0.005$ ). Addition of hirudin or culturing the tumor cells in serum free medium did not alter the difference in release of mitogenic activity (Fig. $7 \mathrm{~B}$ ), consistent with the inability of coumadin to reverse the growth induction by tissue factor in vivo. Therefore the effect of tissue factor on tumor cell mediated angiogenesis is independent of thrombin formation.

Since angiogenesis results from a balance of angiogenic and antiangiogenic activities, we tested the stable transfected Meth-
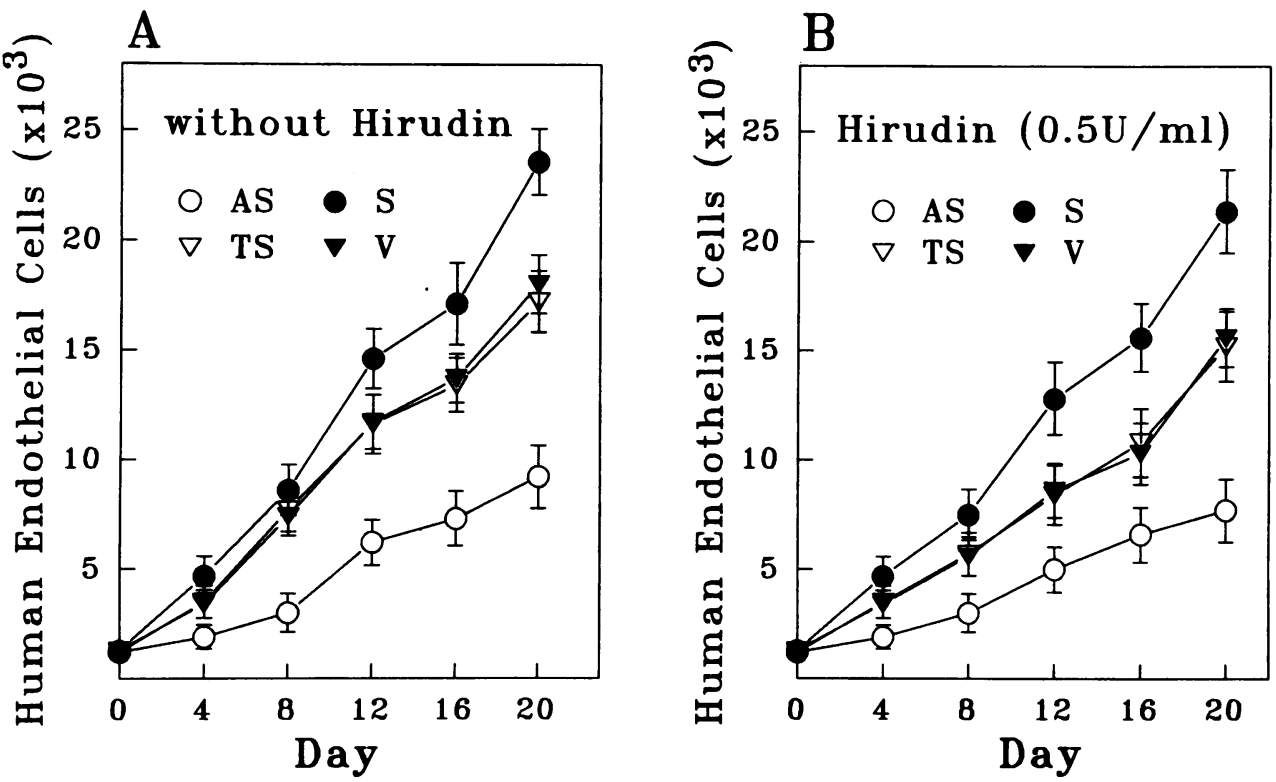

Figure 7. Effect of tissue factor on release of mitogenic activity for endothelial cells. Conditioned supernatant of stable transfectants in RPMI 1640 was added to freshly plated human umbilical vein endothelial cells. Conditioned supernatants were prepared by culturing Meth-A cells in the absence $(A)$ or presence $(B)$ of hirudin. Endothelial cells were counted at the indicated times ( see Methods). Conditioned supernatant from tissue factor overexpressing cells (sense) had the strongest mitogenic activity, followed by the truncated sense or vector transfected line. Differences between sense and controls (vector or truncated sense) were significant $(P<0.05)$ after day 12. The lowest mitogenic activity towards endothelial cells was present in antisense transfected

Meth-A cells, not expressing tissue factor $(P<0.005)$ after day 8 . The experiment was repeated four times and with three independently transfected cell lines. Each point with the bar shows the mean and SD $(n=4 \times 18)$. Abbreviations are as in Fig. 1 . 


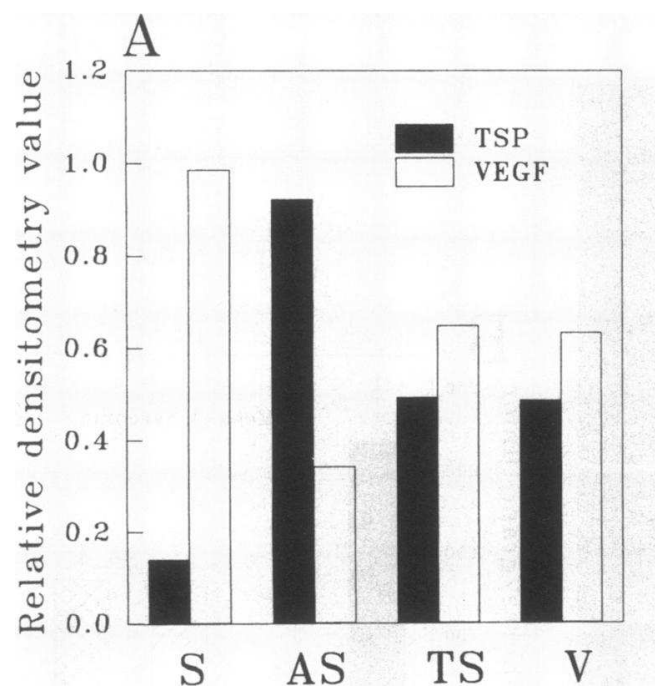

A sarcoma cell lines with respect to the transcriptional activity of the angiogenic, VEGF/VPF and the antiangiogenic thrombospondin. Nuclear run on analysis of Meth-A cells growing in vitro demonstrated a higher transcriptional rate for the endothelial cell mitogen VPF/VEGF, and a lower rate for the antiangiogenic thrombospondin in cell lines transfected with sense, compared with vector, truncated sense or antisense (Fig. $8 \mathrm{~A}$ ). In contrast antisense tissue factor transfectants had a decreased rate of VEGF/VPF transcription and a higher rate of thrombospondin transcription. These data suggest that tissue factor expression is closely correlated with induction of a tumor-derived angiogenic factor, VPF/VEGF, which has been speculated to have an important role in tumor growth (24-29). This has also been confirmed by Northern analysis (Fig. 8 B) of Meth-A sarcoma cells. Thus tissue factor expression influences expression the angiogenic VEGF/VPF and the antiangiogenic thrombospondin.

\section{Discussion}

These data suggest the possible significance of tissue factor as an immediate early gene $(8,9)$ : coordinate expression of tissue factor with induction of cell proliferation allows the tumor cells to more effectively elicit a neoangiogenic response critical for their growth and survival in vivo. Tissue factor, which shares distant homologies with the gene superfamily of receptors for hematopoietic growth factors and cytokines, can also be considered a "competence gene," an alternative name assigned to the "immediate early genes" $(10,30-34)$, which facilitates endothelial cell ingrowth and capillary formation by "progression factors," the angiogenesis factors. However it remains unclear if the link of tissue factor expression to angiogenesis is present in all cells or only in Meth-A sarcoma and B-16 melanoma (data not shown) studied here.

Tumors are frequently surrounded by fibrin, suggesting that tissue factor overexpression might be due to tissue factor-factor $\mathrm{VII}_{\mathrm{a}}$-dependent thrombin formation. To exclude this possibility, mice were anticoagulated with coumadin. Anticoagulation of mice with coumadin did not affect growth induction observed in tumors overexpressing tissue factor. Furthermore, the difference in the mitogenic effects of tissue factor sense, truncated sense, vector, and antisense transfectants on the growth of endothelial cells was not decreased in serum free medium or by the addition of hirudin. Therefore the effect of tissue factor on tumor growth, vascularization, and elaboration of angiogenic stimuli appears to be independent of coagulation. This raises the question of the mechanism by which tissue factor elicits an angiogenic response in the tumors tested.

In this study we show that transcription of an important mediator of angiogenesis, VPF/VEGF is induced by stable transfection of tumor cells with tissue factor cDNA in the sense orientation, but suppressed when cells were transfected with tissue factor cDNA in the antisense orientation. The mechanism linking expression of tissue factor to thrombospondin and VPF/ VEGF expression remains to be elucidated. One possible route by which tissue factor might influence expression of other genes is through phosphorylation of its cytoplasmic tail. However, to date, neither the signals required for inducing phosphorylation nor the intracellular events dependent on phosphorylation of tissue factor are known. Future studies with tissue factor mutants lacking the phosphor acceptor side will be necessary to clarify if phosphorylation of tissue factor results in alteration of gene expression.

These studies emphasize the integral role that tissue factor has in tumor biology, in addition to its well known function as the central procoagulant cofactor which initiates activation of the coagulation pathway.

\section{Acknowledgments}

We thank Drs. Risau and Habenicht, Germany, for helpful comments.

This work was supported by a grant from the Deutsche Forschungsgemeinschaft and Mildred Scheel Stiftung (P. Nawroth). P. Nawroth was supported by a Heisenberg Stipend from DFG. D. Stern was supported by National Institutes of Health grants HL 42833 and HL 21006.

\section{References}

1. Nemerson, Y. 1988. Tissue Factor and hemostasis. Blood. 71:1-8.

2. Bach, R. Tissue Factor. Crit. Rev. Biochem. 1988. 23:339-368.

3. Weiss, H. J., and B. Lages. 1988. Evidence for tissue-factor dependent activation of the classic extrinsic coagulation mechanism in blood obtained from bleeding wounds. Blood. 71:629-635. 
4. Drake, Th. A., J. H. Morrissey, and T. S. Edgington. 1989. Selective cellular expression of tissue factor in human tissues. Implications for disorders of hemostasis and thrombosis. Am. J. Pathol. 134:1087-1097.

5. Gunji, Y., and E. Gorelik. 1988. Fibrin protects murine tumor cells from destruction by killer cells. Cancer Res. 48:5216-5221.

6. Murray, J. C. 1991. Coagulation and Cancer. Br. J. Cancer. 64:422-424.

7. Markus, G. 1984. The role of hemostasis and fibrinolysis in the metastatic spread of cancer. Semin. Thromb. Hemostasis. 10:61-70.

8. Blatti, S. P., D. N. Foster, G. Ranganath, H. L. Moses, and M. J. Getz. 1988. Induction of fibronectin gene transcription and mRNA is a primary response to growth factor stimulation of AKB-2B cells. Proc. Natl. Acad. Sci. USA. 85:1119-1123.

9. Almendral, J. M., D. Sommer, H. McDonald-Bravo, J. Burckhardt, J. Perera, and R. Bravo. 1988. Complexity of the early genetic response to growth factors in mouse fibroblasts. Mol. Cell. Biol. 8:2140-2148.

10. Hartzell, S., K. Ryder, A. Lanahan, L. Lau, and D. Nathans. 1989. A growth factor responsive gene of murine BALB/c 3T3 cells encodes a protein homologous to human tissue factor. Mol. Cell. Biol. 9:2567-2573.

11. Boulter, C. A., and E. F. Wagner. 1987. An universal retroviral vector for efficient constitutive expression of exogenous genes. Nucleic Acids Res. 15:7194.

12. Stewart, C. L., M. Vanek, and E. F. Wagner. 1985. Expression of foreign genes from retroviral vectors in mouse teratocarcinoma chimeras. EMBO (Eur. Mol. Biol. Organ.) J. 4:3701-3709.

13. Felgner, P. L., and T. R. Gadek. 1987. Lipofectin: a highly efficient, lipid mediated DNA-transfection procedure. Proc. Natl. Acad. Sci. USA. 84:74137416.

14. Stern, D. M., J. Brett, K. Harris, and P. P. Nawroth. 1986. Participation of endothelial cells in the protein C-protein $\mathrm{S}$ anticoagulant pathway: the synthesis and release of protein S. J. Cell Biol. 102:1971-1978.

15. Nawroth, P. P., and D. M. Stern. 1986. Modulation of endothelial cell hemostatic properties by tumor necrosis factor. J. Exp. Med. 163:740-745.

16. Larsson, L. I. 1988. "Immunocytochemistry: Theory and Practice." CRC Press, Inc., Boca Raton, FL. 95 pp.

17. Kaplow, L. S. 1974. Cytologic studies of hematopoietic cells by interference contrast (Nomarski) optics. Am. J. Clin. Pathol. 63:451-456.

18. Nawroth, P., D. Handley, G. Matsueda, R. DeWaal, H. Gerlach, D. Blohm, and D. Stein. 1989. Tumor necrosis factor/cachectin-induced intravascular fibrin formation in Meth A fibrosarcomas. J. Exp. Med. 168:637-647.

19. Nawroth, P. P., I. Bank, D. Handley, J. Cassimeris, L. Chess, and D. M. Stern. 1986. Tumor necrosis factor/cachectin interacts with endothelial cell receptors to induce release of interleukin 1. J. Exp. Med. 163:1363-1375.
20. Greenberg, M. E., and E. B. Zifff. 1984. Stimulation of 3T3 cells induces transcription of the c-fos protooncogene. Nature (Lond.). 311:433-438.

21. Feinberg, A. P., and B. Vogelstein. 1983. A technique for radiolabelling DNA restriction endonuclease fragments to high specific activity. Anal. Biochem. 1132:6-13.

22. Chirgwin, J. M., A. E. Przbyla, R. J. Macdonald, and W. J. Rutter. 1979. Isolation of biologically active ribonucleic acid from sources enriched in ribonuclease. Biochemistry. 18:5294-5299.

23. Sawdey, M., T. J. Podor, and D. J. Loskutoff. 1989. Regulation of type 1 plasminogen activator inhibitor gene expression in cultured bovine aortic endothelial cells. J. Biol. Chem. 264:10396-10401.

24. Folkman, J., and Y. Shing. 1992. Angiogenesis. J. Biol. Chem. 267:10931 10934.

25. Plate, K. H., G. Breier, H. Weich, and W. Risau. 1992. Vascular endothelial cell growth factor is a potent tumor angiogenesis factor in human gliomas in vivo. Nature (Lond.). 359:845-848.

26. Shweiki, D., A. Itin, D. Soffer, and E. Keshet. 1992. Vascular endothelial growth factor induced by hypoxia-initiated angiogenesis. Nature (Lond.). 359:843-845.

27. Breier, G., U. Albrecht, S. Sterrer, and W. Risau. 1992. Expression of vascular endothelial growth factor during embryonic angiogenesis and endothelial cell differentiation. Development (Camb.). 114:521-532.

28. Connolly, D., D. Heuvelman, R. Nelsoon, J. Olander, B. Eppley, J. Delfino, N. Siegel, R. Leimgruber, and J. Feder. 1989. Tumor vascular permeability factor stimulates endothelial cell growth and angiogenesis. J. Clin. Invest. 84:14701481 .

29. Ferrra, N., J. Winer, T. Burton, A. Rowland, M. Siegel, H. Phillips, T. Terrell, G. Keller, and A. Levonson. 1993. Expression of vascular endothelia growth factor does not promote transformation but confers a growth advantage in vivo in chinese hamster ovary cells. J. Clin. Invest. 91:160-167.

30. Salser, W., A. Bolle, and R. Epstein. 1970. J. Mol. Biol. 49:271-295.

31. Grasso, R., and J. Buchanan. 1969. Synthesis of early RNA in bacteriophages T4 infected E. coli B. Nature (Lond.). 224:882-885.

32. Cochran, B. H., A. C. Reffel, and C. D. Stiles. 1983. Molecular cloning of gene sequences regulated by platelet derived growth factor. Cell. 33:939-947.

33. Zullo, J. N., B. H. Cochran, A. S. Huang, and C. D. Stiles. 1985. Platelet derived growth factor and double stranded ribonucleic acids stimulate expression in the same genes in 3T3-cells. Cell. 43:793-800.

34. Pledger, W. J., C. D. Stiles, C., H. N. Antoniades, and C. D. Scher. 1977. Induction of DNA synthesis in Balb/c3T3 cells by serum components: reevaluation of the commitment process. Proc. Natl. Acad. Sci. USA. 74:44814485 . 